\title{
Pneumoperitoneum, pneumoretroperitoneum, pneumothorax, and subcutaneous emphysema findings in a case of perforation after colonoscopy
}

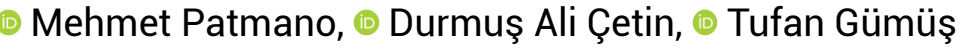 \\ Department of General Surgery, Şanlıurfa Training and Research Hospital, Şanlıurfa, Turkey
}

\begin{abstract}
Colonoscopy is a widely used method for diagnosis and treatment. Endoscopic examination of the colon and rectum is performed for various purposes, including screening for and monitoring of colorectal cancer. Perforation after colonoscopy is rare; the occurrence is reported to be approximately $0.15-0.19 \%$. A 54-year-old male patient presented at the emergency department with abdominal pain 8 hours after a colonoscopy, which had been completed without any known problem. Examination revealed pneumothorax, pneumoretroperitoneum, intraperitoneal air, and subcutaneous emphysema. The patient was hospitalized for observation and treatment, without any signs of peritoneal irritation or leukocytosis. The patient was subsequently discharged without complications. The aim of this study was to analyze the clinical presentation, diagnosis, and treatment of a patient who developed retroperitoneal air, pneumoperitoneum, pneumothorax, and subcutaneous emphysema following a colonoscopy procedure.
\end{abstract}

Keywords: Colonoscopy; emphysema; perforation.

\section{Introduction}

Colonoscopy is a visual examination of large intestine (colon) performed with light fiberoptic or videoendoscope. Endoscopic examination is the most effective method to investigate the symptoms associated with the large intestine. The aim of the colonoscopy is to visualize the colon up to the cecum. It is also able to allow interventions for bleeding and is used therapeutically for volvulus decompression. Complications related to endoscopy may be related to the preparation of the procedure (such as hypotension and electrolyte imbalance following mechanical bowel preparation) or directly to endoscopic procedures (such as postpolipectomy bleeding and colon perforation). Perforation is rarely seen after colonoscopy and it is reported to be approximately $0.15-0.19 \% 0^{[1,2]}$ The incidence of colon perforation in diagnostic colonoscopy may be as low as $0.02 \%$ and as high as $0.6 \%$ in therapeutic colonoscopy. ${ }^{[3]}$ Perforation in the colon can rapidly cause peritonitis and even sepsis. These complications imply high morbidity and mortality. Sub-diaphragmatic air, intraperitoneal air, pneumoretroperitoneum, pneumomediastinum, pneumothorax and subcutaneous emphysema may be observed after colon perforation. The aim of this study was to analyze the clinical presentation, diagnosis 
and treatment of retroperitoneal air, pneumoperitoneum, pneumothorax and subcutaneous emphysema after colonoscopy.

\section{Case Report}

A 54-year-old male patient presented with long-term abdominal pain and constipation. Complete colonoscopy was performed under sedation. There was no pathology in the colon segments and rectum. The process was terminated without any problem. 8 hours after colonoscopy, he presented to the emergency department with abdominal pain and back pain. Physical examination revealed crepitation of the anterior neck and chest wall. 8 hours after colonoscopy, he presented to the emergency department with abdominal pain and back pain. Physical examination revealed crepitation of the anterior neck and chest wall. His abdominal examination was unremarkable. Laboratory tests revealed that the white blood cell was $14300 / \mathrm{mm}^{3}$, hemoglobin: $14.3 \mathrm{~g} / \mathrm{dL}$, and hematocrit: 40.9\%. Direct abdominal X-ray (ADBG) showed sub-diaphragmatic free air (Fig. 1). The patient underwent thoracic and abdominal computed tomography (CT). Pneumothorax, pneumoretroperitoneum, intraperitoneal air and subcutaneous emphysema were present (Figs. 2-4). The patient was hospitalized for observation without any signs of peritoneal irritation and leukocytosis. Because of pneumothorax, chest tube was inserted by thoracic surgery clinic. Oral intake was closed and antibiotherapy was arranged. On the $3^{\text {rd }}$ day of the follow-up, the patient had abdominal examination and gas stool discharge and oral aqueous food was started and gradually increased. On the $6^{\text {th }}$ day the chest tube pneumothorax regressed

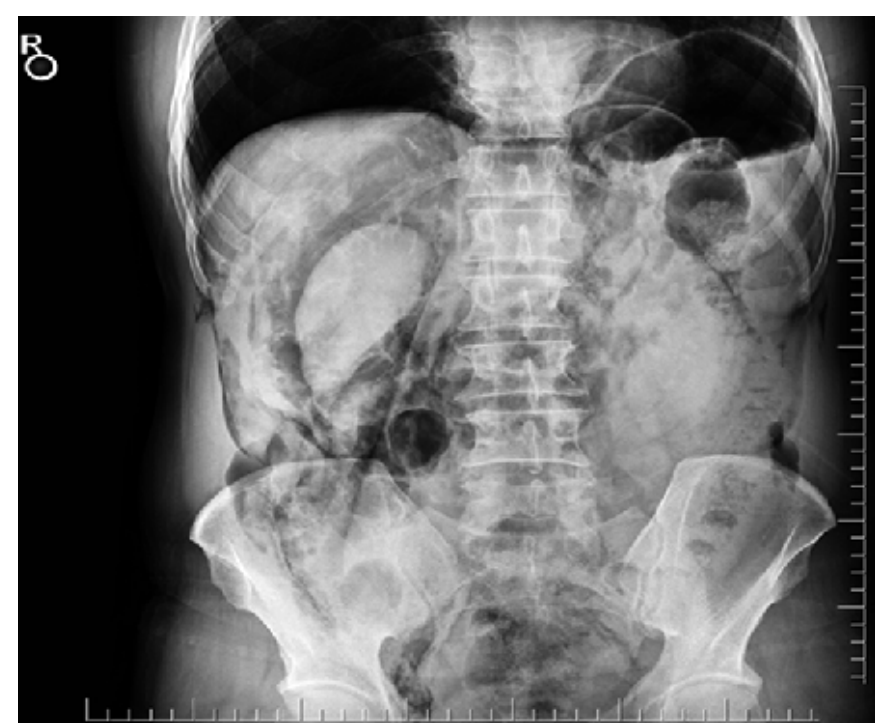

Figure 1. Direct abdominal X-ray subdiaphragmatic free air.

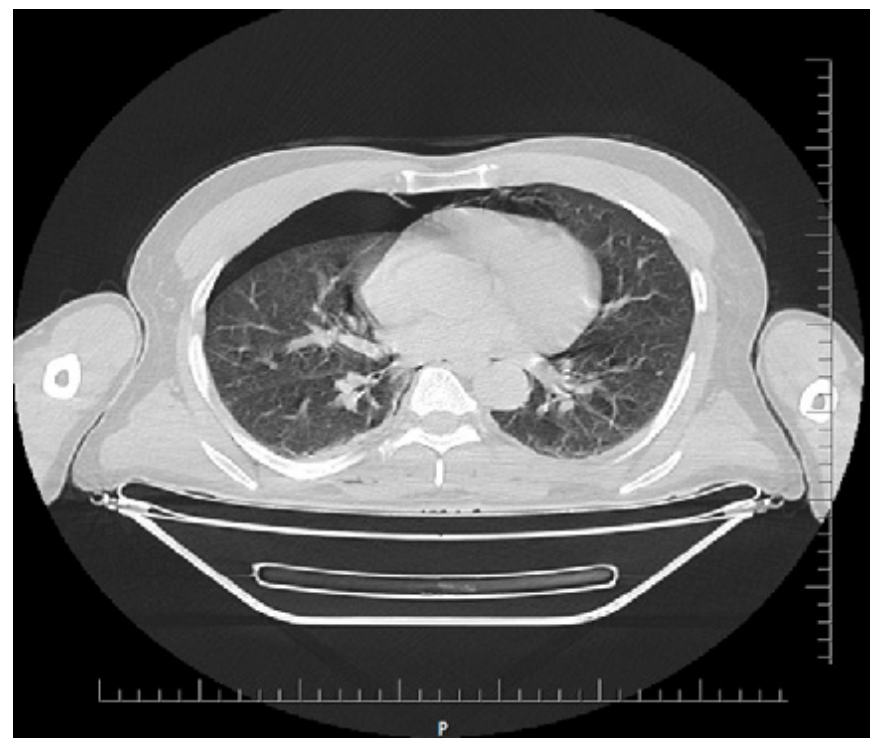

Figure 2. Axial thorax CT Pneumothorax.

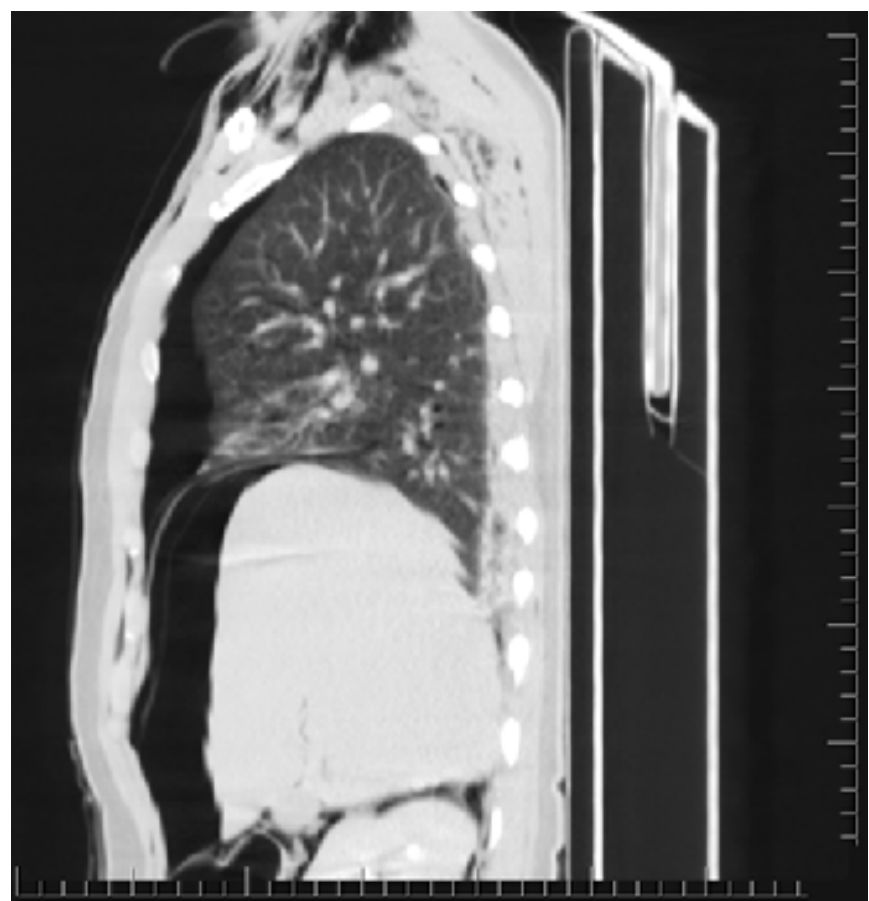

Figure 3. Coronal abdominal and thorax CT Pneumothorax and intraperitoneal free air.

and the patient tolerated oral intake and was discharged without any problem.

\section{Discussion}

In colorectal diseases, colonoscopy is widely used as a diagnostic and therapeutic tool. There are many complications associated with colonoscopy. The most common complication is bleeding. Perforation occurs less frequently but is the most serious complication. Many different mechanisms have been proposed to cause per- 


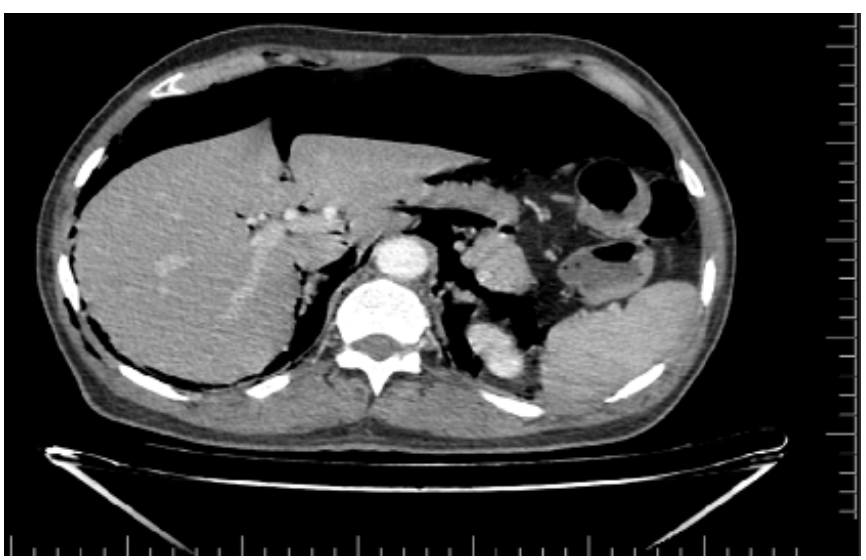

Figure 4. Pneumoretroperitoneum and intraperitoneal free air.

foration. These include pneumatic, mechanical and therapeutic perforation. Mechanical injury causes the largest holes, while electrocautery injury causes the smallest holes. Patient risk factors included anticoagulation status, extensive contamination, active malignancy, history of hospitalization, delayed diagnosis, and steroid use. ${ }^{[4]}$ The frequency of perforation increases in patients with colonic mass, diverticulum, inflammatory bowel diseases and patients with previous abdominal surgery. ${ }^{[5]}$ In our patient, there was no therapeutic procedure that might cause perforation. In the presence of perforation, extra colonic air can cross the layers of retroperitoneal tissue and cause subcutaneous emphysema in the neck, armpit, anterior chest wall and scrotum. In addition, pneumothorax, pneumopericardium, pneumomediastinum and pneumatosis may cause cystoides intestinalis. ${ }^{[6-8]}$

Cho et al. ${ }^{[9]}$ reported numerous subdiaphragmatic free air in all perforation cases caused by diagnostic endoscopy and in almost $45 \%$ of therapeutic perforation cases. Therefore, abdominal roentgenogram is a cost-effective and useful method for detecting the presence of subdiaphragmatic free air with a positive predictive value of 92\%. ${ }^{[10]}$ However, sometimes subdiaphragmatic free air cannot be detected by abdominal $\mathrm{x}$-ray. In this setting, computed tomography can provide great assistance in the diagnosis of free air, micro-holes and/or abscesses. Patients who are clinically unstable or exhibit peritonitis on physical examination require immediate investigation. In our patient, ADBG was detected under six diaphragmatic free air and air. Thorax and abdominal CT showed diffuse intraperitoneal and retroperitoneal air. In addition, pneumothorax and subcutaneous emphysema were observed in the neck and anterior chest wall.

There are three approaches to perforations after colonoscopy. These are conservative, endoscopic and surgical approaches. Conservative approach includes bed rest, cessation of oral intake, broad-spectrum antibiotic therapy and close monitoring with imaging methods. Patients treated conservatively constitute a small portion of all perforations, and the findings of the cases regress in 24 hours. These patients usually have retroperitoneal perforation and/or post-therapeutic perforation. ${ }^{[5]}$ Endoscopic approach has been reported to successfully close with clips. However, large ( $>10 \mathrm{~mm}$ ) holes that occur during diagnostic colonoscopy are considered contraindications to endoscopic closure. ${ }^{[11]}$

Since our patient was clinically stable, there were no sepsis and peritonitis findings, and bowel cleansing was performed, surgical intervention was not considered in the first plan. The patient was treated conservatively without any significant change in clinical, laboratory and imaging methods during follow-up. As a result; Perforation can be seen, although rare, due to colonoscopy. In addition, intraperitoneal air, pneumomediastinum, pneumoretroperitoneum and subcutaneous emphysema may accompany perforation. Conservative approach should be kept in mind as a treatment option in patients without evidence of peritoneal irritation.

\section{Disclosures}

Informed Consent: Written informed consent was obtained from the patient for the publication of the case report and the accompanying images.

Peer-review: Externally peer-reviewed.

Conflict of Interest: None declared.

Authorship Contributions: Concept - M.P.; Design - M.P., D.A.Ç.; Supervision - D.A.Ç., T.G.; Materials - M.P., T.G.; Data collection and/or processing - M.P., D.A.C..; Analysis and/or interpretation -M.P., T.G.; Literature search - M.P., D.A.Ç.; Writing - M.P.; Critical review - D.A.Ç., T.G.

\section{References}

1. Çetin DA, Gündeş E, Çiyiltepe H, Aday U, Değer KC, Polat E. Rare Complications of an Unproblematic Colonoscopy: Subcutaneous Emphysema, Pneumoretroperitoneum and Pneumomediastinum. Turk J Colorectal Dis 2016;26:1046. [CrossRef]

2. Taku K, Sano Y, Fu KI, Saito Y, Matsuda T, Uraoka T, et al. Iatrogenic perforation associated with therapeutic colonoscopy: a multicenter study in Japan. J Gastroenterol Hepatol 2007;22:1409-14. [CrossRef] 
3. Rathgaber SW, Wick TM. Colonoscopy completion and complication rates in a community gastroenterology practice. Gastrointest Endosc 2006;64:556-62. [CrossRef]

4. Cai SL, Chen T, Yao LQ, Zhong YS. Management of iatrogenic colorectal perforation: From surgery to endoscopy. World J Gastrointest Endosc 2015;7:819-23. [CrossRef]

5. Lohsiriwat V. Colonoscopic perforation: incidence, risk factors, management and outcome. World J Gastroenterol 2010;16:425-30. [CrossRef]

6. Maunder RJ, Pierson DJ, Hudson LD. Subcutaneous and mediastinal emphysema. Pathophysiology, diagnosis, and management. Arch Intern Med 1984;144:1447-53. [CrossRef]

7. Marwan K, Farmer KC, Varley C, Chapple KS. Pneumothorax, pneumomediastinum, pneumoperitoneum, pneumoretroperi- toneum and subcutaneous emphysema following diagnostic colonoscopy. Ann R Coll Surg Engl 2007;89:W20-W1.

8. Webb T. Pneumothorax and pneumomediastinum during colonoscopy. Anaesth Intensive Care 1998;26:302-4.

9. Cho SB, Lee WS, Joo YE, Kim HR, Park SW, Park $\mathrm{CH}$, et al. Therapeutic options for iatrogenic colon perforation: feasibility of endoscopic clip closure and predictors of the need for early surgery. Surg Endosc 2012;26:473-9. [CrossRef]

10. Iqbal CW, Chun YS, Farley DR. Colonoscopic perforations: a retrospective review. J Gastrointest Surg 2005;9:1229-35.

11. Trecca A, Gaj F, Gagliardi G. Our experience with endoscopic repair of large colonoscopic perforations and review of the literature. Tech Coloproctol 2008;12:315-22. [CrossRef] 